\title{
Interfacial Water Structure as a Descriptor for Its Electro-Reduction on $\mathrm{Ni}(\mathrm{OH})_{2}$-Modified $\mathrm{Cu}(111)$
}

Andrea Auer, Francisco J. Sarabia, Daniel Winkler, Christoph Griesser, Víctor Climent,* Juan M. Feliu, and Julia Kunze-Liebhäuser*

Cite This: ACS Catal. 2021, 11, 10324-10332

Read Online

\section{ACCESS 1}

山ll Metrics \& More

Article Recommendations

Supporting Information

ABSTRACT: The hydrogen evolution reaction (HER) has been crucial for the development of fundamental knowledge on electrocatalysis and electrochemistry, in general. In alkaline media, many key questions concerning $\mathrm{pH}$-dependent structureactivity relations and the underlying activity descriptors remain unclear. While the presence of $\mathrm{Ni}(\mathrm{OH})_{2}$ deposited on $\mathrm{Pt}(111)$ has been shown to highly improve the rate of the HER through the electrode's bifunctionality, no studies exist on how low coverages of $\mathrm{Ni}(\mathrm{OH})_{2}$ influence the electrocatalytic behavior of $\mathrm{Cu}$ surfaces, which is a low-cost alternative to Pt. Here, we demonstrate that $\mathrm{Cu}(111)$ modified with 0.1 and 0.2 monolayers $(\mathrm{ML})$ of $\mathrm{Ni}(\mathrm{OH})_{2}$ exhibits an unusual non-linear activity trend with increasing coverage. By combining in situ structural investigations with studies on the interfacial water orientation using electrochemical scanning tunneling microscopy and laser-induced temperature jump experiments, we find a correlation between a particular threshold of surface roughness and the decrease in the ordering of the water network at the interface. The highly disordered water ad-layer close to the onset of the HER, which is only present for $0.2 \mathrm{ML}$ of $\mathrm{Ni}(\mathrm{OH})_{2}$, facilitates the reorganization of the interfacial water molecules to accommodate for charge transfer, thus enhancing the rate of the reaction. These findings strongly suggest a general validity of the interfacial water reorganization as an activity descriptor for the HER in alkaline media.

KEYWORDS: hydrogen evolution reaction, $\mathrm{Cu}$ single crystals, $\mathrm{Ni}(\mathrm{OH})_{2}$ modification, in situ electrochemical scanning tunneling microscopy, potential of maximum entropy, interfacial water reorganization, laser-induced temperature jump

\section{INTRODUCTION}

The hydrogen evolution reaction (HER) and its electrocatalytic characteristics are central to a number of technologically important processes in the development of hydrogenbased energy sources, a pivotal alternative to fossil fuels. The HER is an ideal model reaction and hence of fundamental scientific importance since it helped to develop basic concepts of modern electrocatalysis. ${ }^{1-3}$ While in acidic media it is generally accepted that the hydrogen binding energy (HBE) is the sole activity descriptor, there is much debate on the energetics and kinetics of the alkaline HER. ${ }^{4}$ Markovic and coworkers have continuously pointed out that in alkaline solutions there is a second descriptor: the binding and energetics of adsorbed hydroxyl species $\left.\left(\mathrm{OH}_{\mathrm{ad}}\right)\right)^{5-9}$ In previous works, they have shown the importance of favorable $\mathrm{OH}$ adsorption, which seems to enhance the rate of water dissociation by lowering the energy barrier for $\mathrm{H}_{2} \mathrm{O}$ activation through a metal- $-\mathrm{OH}_{\mathrm{ad}}-\mathrm{H}_{2} \mathrm{O}$ complex. ${ }^{5,7,10}$ It is further stated that by incorporating more oxophilic sites, which offer a stronger $\mathrm{OH}$ binding, catalysts show an enhanced activity toward the HER in alkaline media. ${ }^{5,8,10}$ This led to the idea of modifying platinum $(\mathrm{Pt})$, the state-of-the-art catalyst for the HER due to its optimal HBE, with more oxophilic species, i.e.,
$\mathrm{Ni}(\mathrm{OH})_{2}$ ad-islands. ${ }^{6}$ The resulting bifunctional catalyst shows a significantly improved activity, where, mechanistically, the randomly distributed $\mathrm{Ni}(\mathrm{OH})_{2}$ clusters promote the dissociation of water and thereby enhance the formation of adsorbed hydrogen $\left(\mathrm{H}_{\mathrm{ad}}\right)$ intermediates, which are collected by the $\mathrm{Pt}$ substrate and subsequently recombined to form $\mathrm{H}_{2}{ }^{6}$ In accordance with these observations, it has been shown on $\mathrm{Pt}(111)$ decorated with different $3 \mathrm{~d}$ transition metal hydroxides that the affinity of the oxophilic sites to $\mathrm{OH}_{\mathrm{ad}}$ should neither be too strong nor too weak to promote the HER activity in alkaline media.?

In addition to this bifunctional mechanism, it was suggested by the groups in Alicante and Leiden that $\mathrm{Ni}(\mathrm{OH})_{2}$ promotes the HER by lowering the energy barrier associated with the reorganization of the interfacial water network, which then allows for an easier charge transfer through the double

Received: June 14, 2021

Revised: July 21, 2021

Published: August 4, 2021 
layer. ${ }^{11,12}$ Through modification of $\mathrm{Pt}$ with $\mathrm{Ni}(\mathrm{OH})_{2}$ islands, the electric field strength decreases significantly due to a negative shift of the potential of zero free charge (pzfc) or the potential of maximum entropy (pme). ${ }^{11,12}$

The generality of the promoting effect of adding $\mathrm{Ni}(\mathrm{OH})_{2}$ to a catalyst's surface has been clearly shown for a variety of metals, including IB group metals (i.e., $\mathrm{Cu}, \mathrm{Ag}$, and $\mathrm{Au}$ ). ${ }^{8}$ The validity of the proposed descriptors, however, i.e., the bifunctionality given through oxophilic sites for favorable $\mathrm{OH}_{\mathrm{ad}}$ energetics on the one hand and the strength of the interfacial electric field influencing the energetic barrier associated with water reorganization during proton/hydroxide transfer on the other hand, has only been confirmed for Ptgroup metal-based electrocatalysts. $\mathrm{Cu}$ is a low-cost alternative to Pt-group metals, with a uniquely low tendency toward hydride formation in long-term operations. ${ }^{8}$ In this work, we therefore show that modifying $\mathrm{Cu}(111)$ electrodes with low amounts of $\mathrm{Ni}(\mathrm{OH})_{2}$ leads to an unexpected non-linear activity increase with increasing coverage. Our electrochemical measurements reveal that while adding small amounts of only $0.1 \mathrm{ML}$ of $\mathrm{Ni}(\mathrm{OH})_{2}$ to the $\mathrm{Cu}$ surface does not lead to a significant (kinetic) enhancement of the HER in the alkaline electrolyte, the activity for $0.2 \mathrm{ML}$ of $\mathrm{Ni}(\mathrm{OH})_{2}$ is enhanced by a factor of 13 relative to bare $\mathrm{Cu}(111)$. In situ electrochemical scanning tunneling microscopy (EC-STM) reveals that the morphology of the $\mathrm{Cu}$ surface drastically changes upon $\mathrm{Ni}(\mathrm{OH})_{2}$ deposition, which leads to an increased roughness. While the mean-square roughness of the surface scales linearly with increasing $\mathrm{Ni}(\mathrm{OH})_{2}$ surface concentration, we find its impact on the interfacial water layer structure to be nonuniform. Laser-induced potential transient measurements evidence a potential-dependent water orientation, where a highly disordered interfacial water layer exists close to the onset of the HER for $0.2 \mathrm{ML}$ of $\mathrm{Ni}(\mathrm{OH})_{2}$ only. Water dissociation is thus facilitated by a lower energetic barrier for charge movement across the electrochemical double layer. This molecular-level understanding is an essential step toward unraveling the complexity and determining the general validity of activity descriptors for the HER in alkaline media and enables the development of a more complete structureactivity relation for $\mathrm{Cu}$ composite materials.

\section{RESULTS AND DISCUSSION}

To determine the effect of $\mathrm{Ni}(\mathrm{OH})_{2}$ deposition on the electrochemical behavior of $\mathrm{Cu}(111)$, cyclic voltammetry was employed. All potentials are given with respect to the reversible hydrogen electrode (RHE). Figure la shows the voltammetric profiles of $\mathrm{Cu}(111)$ with different $\mathrm{Ni}(\mathrm{OH})_{2}$ coverages, i.e., 0.1 and $0.2 \mathrm{ML}$, in $0.1 \mathrm{M} \mathrm{NaOH}$. The blank voltammogram without $\mathrm{Ni}(\mathrm{OH})_{2}$ is also shown as reference. A distinct peak pair, corresponding to the adsorption and desorption of hydroxide $(\mathrm{OH})$ on $\mathrm{Cu}(111)$, with maxima at around $0.12 \mathrm{~V}_{\mathrm{RHE}}{ }^{13,14}$ can be observed in the blank voltammogram. This peak significantly decreases in current density with increasing $\mathrm{Ni}(\mathrm{OH})_{2}$ coverage. The clearly defined $\mathrm{OH}$ adsorption feature in the pseudocapacitive region of the $\mathrm{Cu}(111)$ cyclic voltammogram $(\mathrm{CV})$ enables us to estimate the degree of blockage of the $\mathrm{Cu}$ surface and therefore the apparent $\mathrm{Ni}(\mathrm{OH})_{2}$ coverage from the remaining charge (see Figure S1 and Table S1 in the Supporting Information (SI)). Although there are uncertainties and assumptions made in the used coverage determination, clearly the charge of the

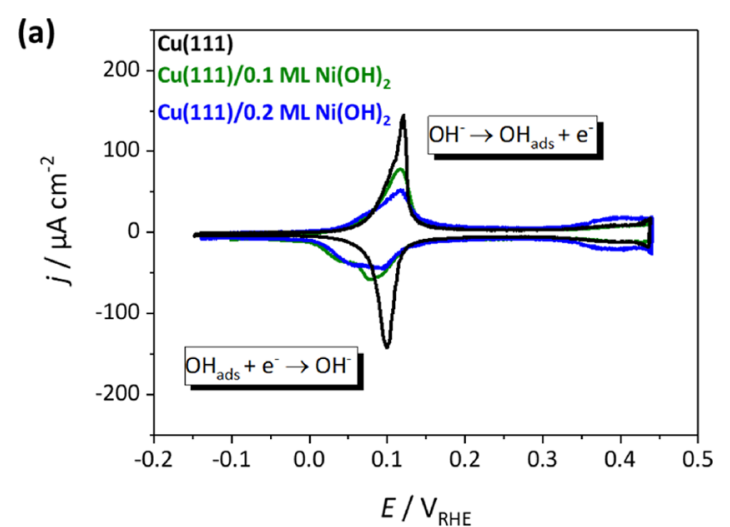

(b)

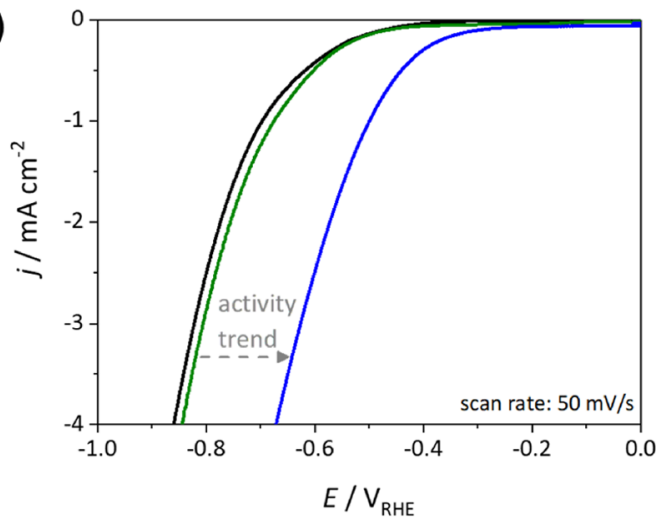

(c)

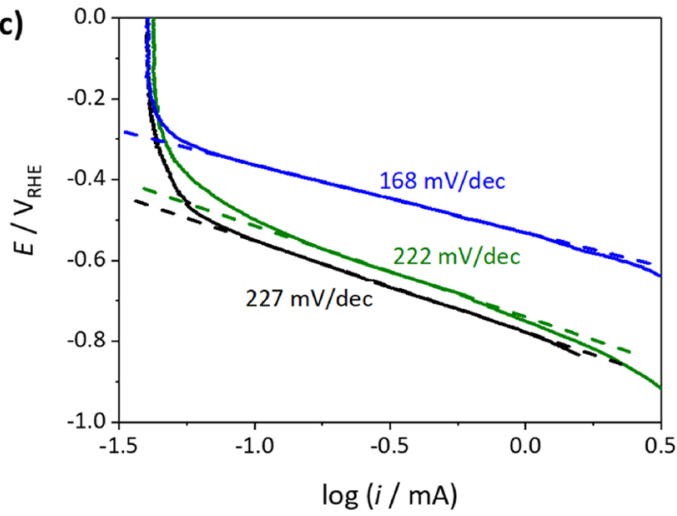

Figure 1. Electrochemical and electrocatalytic properties of $\mathrm{Ni}(\mathrm{OH})_{2-}$ modified $\mathrm{Cu}(111)$ electrodes. (a) Fingerprint cyclic voltammograms (CVs) for $\mathrm{Cu}(111)$ (black), $\mathrm{Cu}(111)$ modified with $0.1 \mathrm{ML}$ of $\mathrm{Ni}(\mathrm{OH})_{2}$ (green), and $\mathrm{Cu}(111)$ with $0.2 \mathrm{ML}$ of $\mathrm{Ni}(\mathrm{OH})_{2}$ (blue) in $0.1 \mathrm{M} \mathrm{NaOH}$ with a scan rate of $50 \mathrm{mV} / \mathrm{s}$. (b) HER activities for $\mathrm{Cu}(111), \mathrm{Cu}(111) / 0.1 \mathrm{ML}$ of $\mathrm{Ni}(\mathrm{OH})_{2}$, and $\mathrm{Cu}(111) / 0.2 \mathrm{ML}$ of $\mathrm{Ni}(\mathrm{OH})_{2}$. (c) Corresponding Tafel plots for the HER calculated from the measurements recorded in the flow cell at $2 \mathrm{mV} / \mathrm{s}$ (see Figure 2a).

fingerprint $\mathrm{OH}$ adsorption feature relatively decreases with increasing $\mathrm{Ni}(\mathrm{OH})_{2}$ surface concentration.

The electrocatalytic properties of the $\mathrm{Ni}(\mathrm{OH})_{2}$-modified $\mathrm{Cu}(111)$ electrodes toward the HER in alkaline media are depicted in Figure 1b. Interestingly, the HER activity is nonlinearly enhanced with increasing $\mathrm{Ni}(\mathrm{OH})_{2}$ coverage. While for $\mathrm{Cu}(111) / 0.1 \mathrm{ML}$ of $\mathrm{Ni}(\mathrm{OH})_{2}$ only a small promoting effect can be observed, the activity increases significantly for $\mathrm{Cu}(111) / 0.2 \mathrm{ML}$ of $\mathrm{Ni}(\mathrm{OH})_{2}$. The commonly accepted mechanism of the HER in alkaline solutions is typically described through a combination of three steps: the Volmer step involves water dissociation $\left(\mathrm{H}_{2} \mathrm{O}+\mathrm{M}+\mathrm{e}^{-} \rightleftharpoons \mathrm{M}-\mathrm{H}_{\mathrm{ad}}+\right.$ $\left.\mathrm{OH}^{-}\right)$and is followed by either the Tafel step $\left(2 \mathrm{M}-\mathrm{H}_{\mathrm{ad}} \rightleftharpoons 2 \mathrm{M}\right.$ 
$\left.+\mathrm{H}_{2}\right)$ or the Heyrovsky step $\left(\mathrm{H}_{2} \mathrm{O}+\mathrm{M}-\mathrm{H}_{\mathrm{ad}}+\mathrm{e}^{-} \rightleftharpoons \mathrm{M}+\mathrm{H}_{2}+\right.$ $\mathrm{OH}^{-}$), where $\mathrm{M}$ stands for any metal acting as a catalyst. ${ }^{4,15}$ Although a rigorous kinetic analysis of the HER is generally difficult and lies beyond the scope of the present work, Tafel plots are depicted in Figure 1c for comparison of their slopes. To estimate those Tafel slopes, polarization curves at $2 \mathrm{mV} / \mathrm{s}$ were recorded in a flow cell (see Figure $2 \mathrm{a}$ ). We find that both
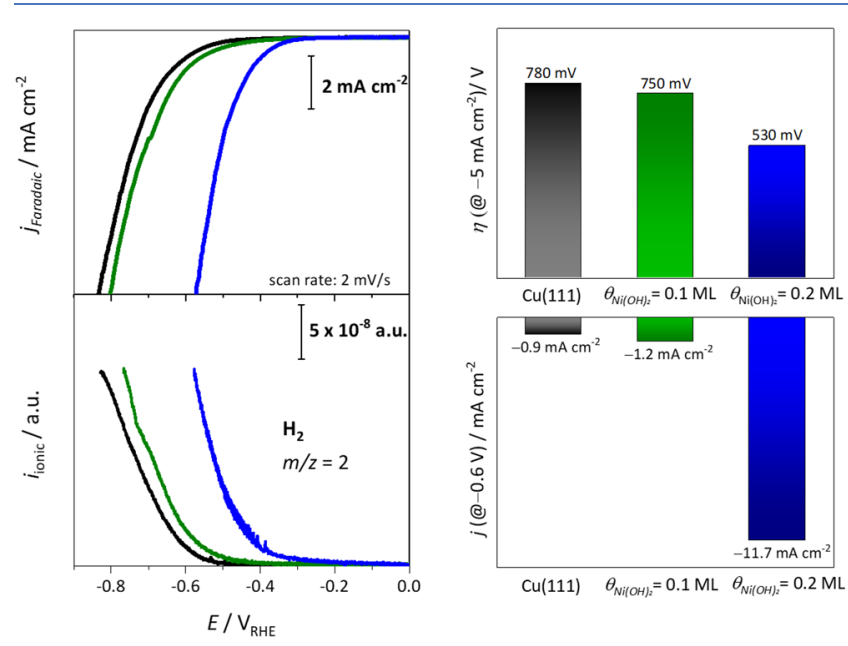

Figure 2. (a) Polarization curves for $\mathrm{Cu}(111)$ (black), $\mathrm{Cu}(111) / 0.1 \mathrm{ML}$ of $\mathrm{Ni}(\mathrm{OH})_{2}$ (green), and $\mathrm{Cu}(111) / 0.2 \mathrm{ML}$ of $\mathrm{Ni}(\mathrm{OH})_{2}$ (blue) with the corresponding $m / z=2$ signal for $\mathrm{H}_{2}$. Comparison between the activities toward the HER expressed as (b) the overpotential at a current density of $-5 \mathrm{~mA} \mathrm{~cm}{ }^{-2}$ and (c) the current density at $-0.6 \mathrm{~V}_{\mathrm{RHE}}$.

the bare $\mathrm{Cu}(111)$ and $\mathrm{Cu}(111) / 0.1 \mathrm{ML}$ of $\mathrm{Ni}(\mathrm{OH})_{2}$ exhibit the same high Tafel slope of $222-227 \mathrm{mV} / \mathrm{dec}$, whereas it decreases to around $168 \mathrm{mV} / \mathrm{dec}$ for a $\mathrm{Ni}(\mathrm{OH})_{2}$ coverage of 0.2 ML. Unexpectedly, this implies that, by decorating $\mathrm{Cu}(111)$ with only $0.1 \mathrm{ML}$ of $\mathrm{Ni}(\mathrm{OH})_{2}$, no kinetic enhancement is obtained, while for slightly higher coverages of $0.2 \mathrm{ML}$ of $\mathrm{Ni}(\mathrm{OH})_{2}$, the significantly lower Tafel slope indicates much faster kinetics. For a more accurate and more quantitative determination of the electrocatalytic behavior of the $\mathrm{Ni}(\mathrm{OH})_{2}$-modified $\mathrm{Cu}(111)$, online differential electrochemical mass spectrometry (DEMS) was employed in a flow cell configuration. The results are shown in Figure 2.

Figure $2 \mathrm{a}$ shows the polarization curves in the potential range of the HER with a scan rate of $2 \mathrm{mV} / \mathrm{s}$ and the corresponding mass-to-charge signal $(m / z=2)$ for $\mathrm{H}_{2}$. The unusual non-linear activity enhancement for $0.2 \mathrm{ML}$ of $\mathrm{Ni}(\mathrm{OH})_{2}$ on $\mathrm{Cu}(111)$ is sustained when the HER activities are considered as either the overpotential $(\eta)$ or the current density. The overpotential at a current density of $-5 \mathrm{~mA} \mathrm{~cm}{ }^{-2}$ is lowered by $30 \mathrm{mV}$ through the presence of $0.1 \mathrm{ML}$ and by $150 \mathrm{mV}$ through $0.2 \mathrm{ML}$ of $\mathrm{Ni}(\mathrm{OH})_{2}$ (see Figure $2 \mathrm{~b}$ ). At $-0.6 \mathrm{~V}_{\mathrm{RHE}}$, the HER current density is enhanced by factors of 1.4 and 13 relative to the bare $\mathrm{Cu}(111)$ for $\mathrm{Ni}(\mathrm{OH})_{2}$ coverages of 0.1 and $0.2 \mathrm{ML}$, respectively (see Figure $2 \mathrm{c}$ ). This is in striking contrast to $\mathrm{Ni}(\mathrm{OH})_{2}$-modified $\mathrm{Pt}(111)$, where a linear increase in activity with increasing coverage of $\mathrm{Ni}(\mathrm{OH})_{2}$ was observed. $^{12}$

To understand this clear difference between $\mathrm{Ni}(\mathrm{OH})_{2}$ modified $\mathrm{Cu}(111)$ and $\mathrm{Pt}(111)$, quasi in situ X-ray photoelectron spectroscopy ${ }^{16}$ was employed to evaluate the chemical composition of the $\mathrm{Cu}(111) / \mathrm{Ni}(\mathrm{OH})_{2}$ electrodes.

Figure $3 \mathrm{a}$ shows the $\mathrm{Cu}$ LMM Auger spectra for each electrode, which are used to determine the different $\mathrm{Cu}$ oxidation states via the relative intensities of the peaks. ${ }^{10,17}$ The relative intensities of the highest peak at a kinetic energy of $\sim 919 \mathrm{eV}$, attributed to $\mathrm{Cu}(0)$ species, $^{18}$ and the peak at $\sim 917 \mathrm{eV}$, ascribed to $\mathrm{Cu}$ (I) species, ${ }^{18}$ remain constant for all samples $(\mathrm{Cu}(0) \gg \mathrm{Cu}(\mathrm{I}))$. This strongly suggests that, by adding $\mathrm{Ni}(\mathrm{OH})_{2}$ to $\mathrm{Cu}(111)$, the $\mathrm{Cu}$ surface remains mostly metallic with an oxidation state of $\mathrm{Cu}(0)$. Interestingly, this differs from previous findings where a clear correlation between higher amounts of $\mathrm{Cu}(\mathrm{I})$ species, and hence a higher oxophilicity of differently treated $\mathrm{Cu}$ surfaces, and the enhancement of the HER activity was proposed. ${ }^{10}$ The Ni $2 \mathrm{p}$ region, shown in Figure $3 \mathrm{~b}$ for the modified $\mathrm{Cu}(111)$ electrodes, reveals the presence of low amounts of oxidized $\mathrm{Ni}$ on the surface. The observed small peaks with binding energies of around 856 and $873 \mathrm{eV}$, corresponding to $\mathrm{Ni} 2 \mathrm{p}_{3 / 2}$ and $\mathrm{Ni}$ $2 \mathrm{p}_{1 / 2}$, with a spin-energy separation of $17 \mathrm{eV}$, are consistent with the literature values reported for $\mathrm{Ni}(\mathrm{OH})_{2} \cdot{ }^{19}$ Our XPS data thus clearly refute that the observed non-linear increase in activity with increasing $\mathrm{Ni}(\mathrm{OH})_{2}$ coverage is related to a difference in the oxidation state of the $\mathrm{Cu}$ surface (i.e., higher amounts of $\mathrm{Cu}(\mathrm{I})$ species). We therefore suspect the unusual activity trends to result from a more fundamental difference between $\mathrm{Cu}$ and $\mathrm{Pt}$. $\mathrm{Cu}$ as a coinage metal has been repeatedly found to dynamically restructure upon anion adsorption, ${ }^{20-24}$ under reaction conditions (e.g., hydrogen evolution, ${ }^{25,26} \mathrm{CO}_{(2)}$ reduction, ${ }^{27-29}$ or $\mathrm{CO}$ oxidation ${ }^{30}$ ), and even at its pzfc. ${ }^{14}$ This gives rise to an inherently much lower stability of $\mathrm{Cu}$ surfaces compared to, e.g., Pt. While decorating $\mathrm{Pt}(111)$ with $\mathrm{Ni}(\mathrm{OH})_{2}$ was found to result in well-separated, randomly distributed
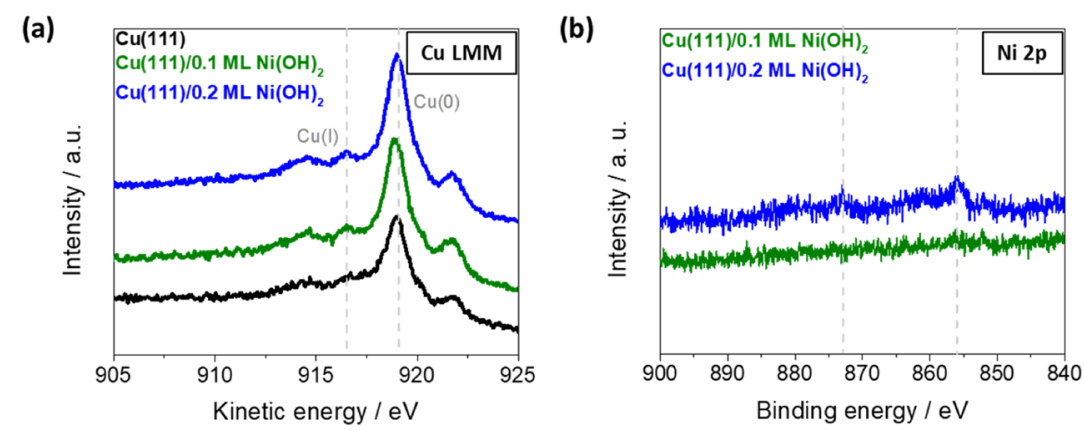

Figure 3. Quasi in situ XPS: (a) Cu LMM Auger signals for $\mathrm{Cu}(111)$ (black), $\mathrm{Cu}(111) / 0.1 \mathrm{ML}$ of $\mathrm{Ni}(\mathrm{OH})_{2}$ (green), and $\mathrm{Cu}(111) / 0.2 \mathrm{ML}$ of $\mathrm{Ni}(\mathrm{OH})_{2}$ (blue), and (b) XPS spectra of the $\mathrm{Ni} 2 \mathrm{p}$ region for $\mathrm{Cu}(111) / 0.1 \mathrm{ML}$ of $\mathrm{Ni}(\mathrm{OH})_{2}$ (green) and $\mathrm{Cu}(111) / 0.2 \mathrm{ML}$ of $\mathrm{Ni}(\mathrm{OH})_{2}(\mathrm{blue})$. All spectra are acquired with a take-off angle of $60^{\circ}$ between the $\mathrm{Cu}(111)$ surface normal and the analyzer. 

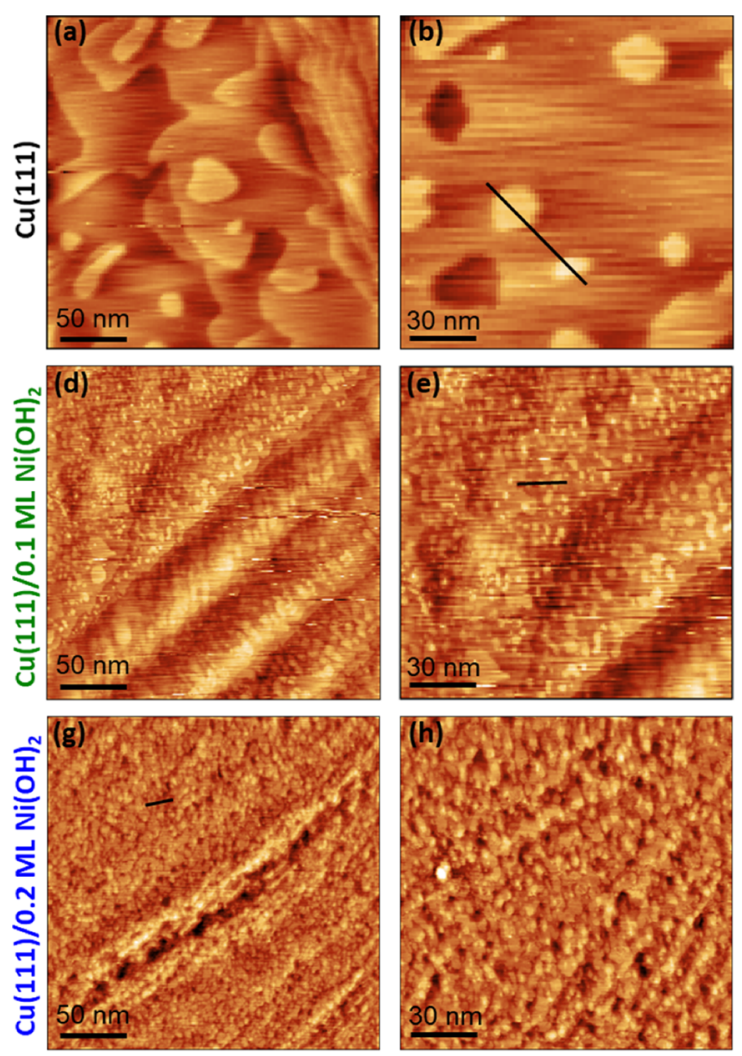
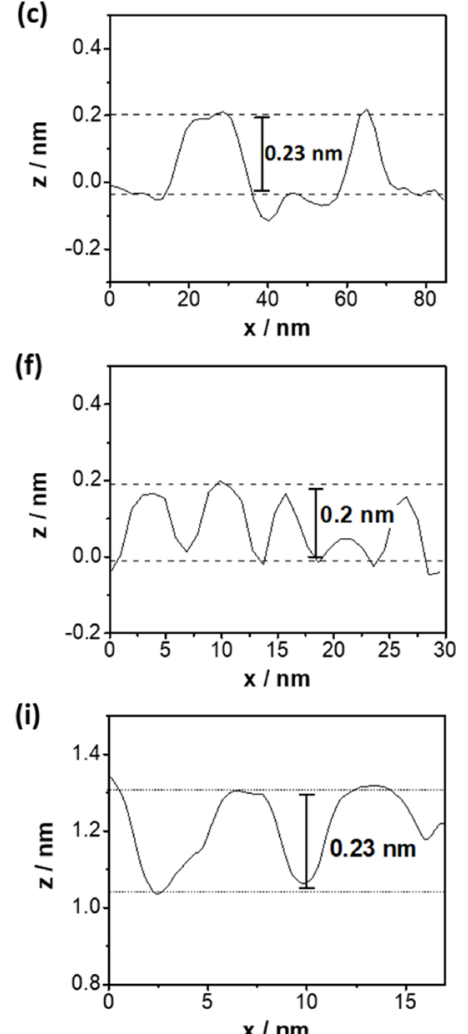

Figure 4. In situ EC STM images of $(\mathrm{a}, \mathrm{b})$ metallic $\mathrm{Cu}(111)$, (d, e) $\mathrm{Cu}(111) / 0.1 \mathrm{ML}$ of $\mathrm{Ni}(\mathrm{OH})_{2}$, and $(\mathrm{g}, \mathrm{h}) \mathrm{Cu}(111) / 0.2 \mathrm{ML}$ of $\mathrm{Ni}(\mathrm{OH})_{2}$ at $-0.05 \mathrm{~V}_{\mathrm{RHE}}$ in $0.1 \mathrm{M} \mathrm{NaOH}$. (c, f, i) Corresponding line profiles for $\mathrm{Cu}(111), \mathrm{Cu}(111) / 0.1 \mathrm{ML}$ of $\mathrm{Ni}(\mathrm{OH})_{2}$, and $\mathrm{Cu}(111) / 0.2 \mathrm{ML}$ of $\mathrm{Ni}(\mathrm{OH})_{2}$. Image sizes are $(250 \times 250) \mathrm{nm}^{2}($ first column $)$ and $(150 \times 150) \mathrm{nm}^{2}($ second column $) . I_{\text {tip }}=1 \mathrm{nA}$ and $E_{\text {tip }}=0.25 \mathrm{~V}_{\mathrm{RHE}}$.

$\mathrm{Ni}(\mathrm{OH})_{2}$ clusters, ${ }^{5,6}$ it is doubtful that the $\mathrm{Cu}$ surface stays intact upon $\mathrm{Ni}(\mathrm{OH})_{2}$ deposition due to its much lower cohesive energy $(3.5 \mathrm{eV}$ vs $5.84 \mathrm{eV}$ for $\mathrm{Pt}) .^{31}$

To assess this hypothesis, we performed in situ EC-STM to investigate the structural and morphological effects of $\mathrm{Ni}(\mathrm{OH})_{2}$ modification on $\mathrm{Cu}(111)$.

As shown in Figure 4a-c, STM imaging of metallic $\mathrm{Cu}(111)$ in $0.1 \mathrm{M} \mathrm{NaOH}$ reveals that the reduced surface exhibits flat terraces with relatively large ad- and vacancy islands $(\sim 20-50 \mathrm{~nm})$ with a monoatomic step height of approximately $0.22 \mathrm{~nm}$. Adding $0.1 \mathrm{ML}$ of $\mathrm{Ni}(\mathrm{OH})_{2}$ leads to the formation and nucleation of additional and much smaller $(\sim 5 \mathrm{~nm}) \mathrm{Cu}$ ad-islands, separated by monolayer steps (see Figure $4 \mathrm{~d}, \mathrm{e})$, which can be deduced from the line profile depicted in Figure 4f. This suggests that the $\mathrm{Cu}(111)$ surface restructures upon the deposition of low amounts of $\mathrm{Ni}(\mathrm{OH})_{2}$. This disintegration of the $\mathrm{Cu}(111)$ surface is even more enhanced for a coverage of $0.2 \mathrm{ML}$ of $\mathrm{Ni}(\mathrm{OH})_{2}$, where the island density is significantly increased (Figure $4 \mathrm{~g}, \mathrm{~h}$ ). For 0.1 $\mathrm{ML}$ of $\mathrm{Ni}(\mathrm{OH})_{2}$, the $\mathrm{Cu}$ ad-islands are well separated revealing the underlying terrace structure, whereas the $\mathrm{Cu}(111)$ surface is dominated by an almost granular-like morphology after adding $0.2 \mathrm{ML}$, conforming to a $3 \mathrm{D}$ roughening, while still exhibiting the thermodynamic shape and monoatomic step height of $\mathrm{Cu}$ ad-islands (Figure 4i). It is well known that $\mathrm{Cu}$ surfaces contain mobile ad-atoms $\left(\mathrm{Cu}_{\mathrm{ad}}\right)$ detached from undercoordinated sites, ${ }^{32}$ which become increasingly mobile upon adding a surfactant, i.e., CO. This leads to a clustering or roughening of the $\mathrm{Cu}$ surface at both the solid/liquid ${ }^{30}$ and solid/gas interfaces. ${ }^{31,33,34}$ Similar to the CO-induced roughening of the $\mathrm{Cu}$ surface, it is plausible that $\mathrm{Ni}(\mathrm{OH})_{2}$ binds to low-coordinated $\mathrm{Cu}$ atoms forming mobile $\mathrm{Ni}(\mathrm{OH})_{2}-\mathrm{Cu}_{\mathrm{ad}}$ complexes, which may migrate over the surface and subsequently aggregate to form $\mathrm{Cu}$ ad-islands, whose size depends on the $\mathrm{Ni}(\mathrm{OH})_{2}$ concentration. $\mathrm{Ni}(\mathrm{OH})_{2}$, although not identifiable in the STM images, clearly stabilizes the roughened $\mathrm{Cu}(111)$ surface, e.g., through lowering of the step edge formation energy. The observed restructuring induced by the deposition of small amounts of $\mathrm{Ni}(\mathrm{OH})_{2}$ and the inherent increase in low-coordinated $\mathrm{Cu}$ sites can help to rationalize the observed increase in activity toward the HER. Interestingly, a closer evaluation of representative statistical quantities of the surfaces, in particular, the mean square roughness, with 61, 112 , and $181 \mathrm{pm}$ for $\mathrm{Cu}(111), \mathrm{Cu}(111) / 0.1 \mathrm{ML}$ of $\mathrm{Ni}(\mathrm{OH})_{2}$, and $\mathrm{Cu}(111) / 0.2 \mathrm{ML}$ of $\mathrm{Ni}(\mathrm{OH})_{2}$, respectively, shows a rather linear increase with increasing coverages (Figure S2 and Table S2). The non-linear trend in activity enhancement with increasing amounts of $\mathrm{Ni}(\mathrm{OH})_{2}$ seems therefore unlikely to result from purely morphological effects, i.e., the roughness factor. However, the possibility that the number of step sites at the restructured $\mathrm{Cu}(111)$ surface is not linearly proportional to the determined mean-square roughness and, thus, the contribution of a difference in activities of step and terrace sites to the observed activity trend cannot be excluded.

While the STM data strongly suggest that a clear differentiation between the active sites represented by $3 \mathrm{D}$ $\mathrm{Ni}(\mathrm{OH})_{2}$ clusters and the bare metal substrate, as observed for modified $\mathrm{Pt}(111)$ electrodes, cannot be easily applied to $\mathrm{Ni}(\mathrm{OH})_{2}$-modified $\mathrm{Cu}(111)$ due to the disintegration of the substrate morphology, the question remains whether we can find a descriptor that allows rationalizing the non-linear activity increase with increasing coverage. Therefore, we performed 

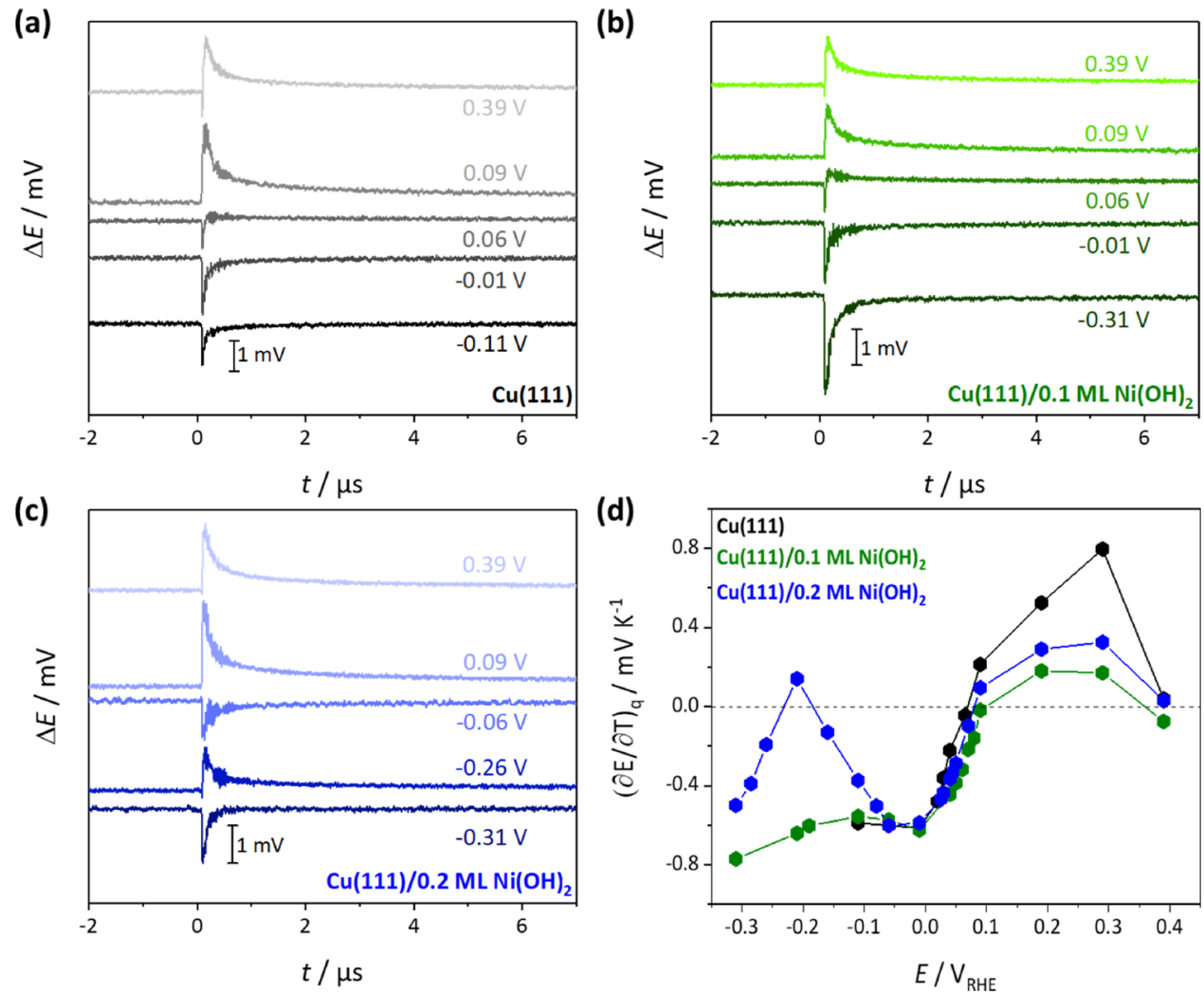

Figure 5. Laser-induced potential transients for (a) the bare $\mathrm{Cu}(111)$, (b) $\mathrm{Cu}(111) / 0.1 \mathrm{ML}$ of $\mathrm{Ni}(\mathrm{OH})_{2}$, and $(\mathrm{c}) \mathrm{Cu}(111) / 0.2 \mathrm{ML}$ of $\mathrm{Ni}(\mathrm{OH})_{2}$ at selected potentials. (d) Thermal coefficients for the electrodes $(a-c)$.

laser-induced temperature jump experiments, which can lead to unraveling the impact of the interfacial water structure reorganization on the rate of the HER in alkaline media. ${ }^{11,12}$

Figure $5 \mathrm{a}-\mathrm{c}$ shows selected laser-induced potential transients for $\mathrm{Cu}(111)$ and $\mathrm{Cu}(111)$ with the two different $\mathrm{Ni}(\mathrm{OH})_{2}$ coverages. The corresponding 3D laser transient plots for $\mathrm{Cu}(111) / 0.1 \mathrm{ML}$ of $\mathrm{Ni}(\mathrm{OH})_{2}$ and $\mathrm{Cu}(111) / 0.2 \mathrm{ML}$ of $\mathrm{Ni}(\mathrm{OH})_{2}$ are shown in Figure $\mathrm{S} 3$ for comparison. We observe, for all investigated electrodes, that at sufficiently high potentials (between 0.35 and $0.1 \mathrm{~V}_{\mathrm{RHE}}$ ), the transients are positive, suggesting that the electric field points away from the surface, and the interfacial water molecules are oriented with the oxygen toward the metal. At around 0.07-0.09 $\mathrm{V}_{\mathrm{RHE}}$, coinciding with the onset of the $\mathrm{OH}$ adsorption peak, the transients change their sign to negative, as was previously shown for bare $\mathrm{Cu}(111)$ electrodes, which suggest that below this potential, a negative free charge resides at the surface. ${ }^{14,35}$ This change of sign is generally attributed to the position of the pme and a turn-over of the water ad-layer. At the pme, water molecules at the interface distribute randomly, and there is no net dipolar contribution to the electrode potential. It is therefore intimately linked to the pzfc since water dipoles orient mainly according to the electric field at the surface. ${ }^{36,37}$ Here, the pme slightly shifts toward more positive potentials upon $\mathrm{Ni}(\mathrm{OH})_{2}$ deposition, exhibiting a trend in the order $\mathrm{Cu}(111)<0.2 \mathrm{ML}$ of $\mathrm{Ni}(\mathrm{OH})_{2}<0.1 \mathrm{ML}$ of $\mathrm{Ni}(\mathrm{OH})_{2}$. At even more negative applied potentials of around $-0.2 \mathrm{~V}_{\mathrm{RHE}}$, the transients for $\mathrm{Cu}(111) / 0.2 \mathrm{ML} \mathrm{Ni}(\mathrm{OH})_{2}$ become positive again in a very narrow potential range close to the onset of the HER before flipping over to negative once more. This means that two changes of the sign from negative to positive can be identified, which consequently shows that two potentials of maximum entropy for double layer formation exist, a phenomenon that was previously found for stepped $\mathrm{Pt}$ surfaces. ${ }^{38}$ Also related to this phenomena, non-monotonous charge variations on $\mathrm{Pt}(111)$ were explained by an electrostatic model of the double layer. ${ }^{39}$ At even lower potentials, the laser transients are all negative, which means that the average water molecule orientation is with the hydrogen toward the metal surface. Introducing a $\mathrm{Ni}(\mathrm{OH})_{2}$ surface concentration of $0.2 \mathrm{ML}$ to the $\mathrm{Cu}(111)$ surface, however, causes a significant decrease in the overall intensity of these transients in the lowest experimentally accessible potential region (see Figure $5 \mathrm{a}-\mathrm{c}$ and Figure S3). This evidences a decrease in the structural order of the interfacial water network close to the onset of the HER for $\mathrm{Cu}(111) / 0.2 \mathrm{ML}$ of $\mathrm{Ni}(\mathrm{OH})_{2}$.

To more quantitatively analyze the laser-induced potential transients, the thermal coefficients of the potential drop across the double layer $(\partial E / \partial T)$ were calculated from linearization of the transients (see description in the Supporting Information and Figure S4 for more details) and are depicted in Figure 5d. Note that the coefficients have been corrected to account for the contribution of the thermodiffusion potential (approximately $\left.-0.43 \mathrm{mV} \mathrm{K}{ }^{-1}\right),^{40}$ which cannot be neglected due to the high mobility of $\mathrm{OH}^{-}$ions (Figure S5). In the potential region negative of $\mathrm{OH}$ adsorption $\left(<0 \mathrm{~V}_{\mathrm{RHE}}\right)$, only a very small decrease in the thermal coefficient $(\partial E / \partial T)$, which can be interpreted in terms of a decrease in the electric field strength, ${ }^{11,36}$ between $\mathrm{Cu}(111)$ and $\mathrm{Cu}(111) / 0.1 \mathrm{ML} \mathrm{Ni}$ $(\mathrm{OH})_{2}$ is observed. For coverages of $0.2 \mathrm{ML}$ of $\mathrm{Ni}(\mathrm{OH})_{2}$ on the other hand, we find a peak-shaped potential dependence of the thermal coefficient with a maximum at around $-0.2 \mathrm{~V}_{\mathrm{RHE}}$, in agreement with three turn-overs of the water layer. This is perfectly consistent with the existence of two pme values (see 

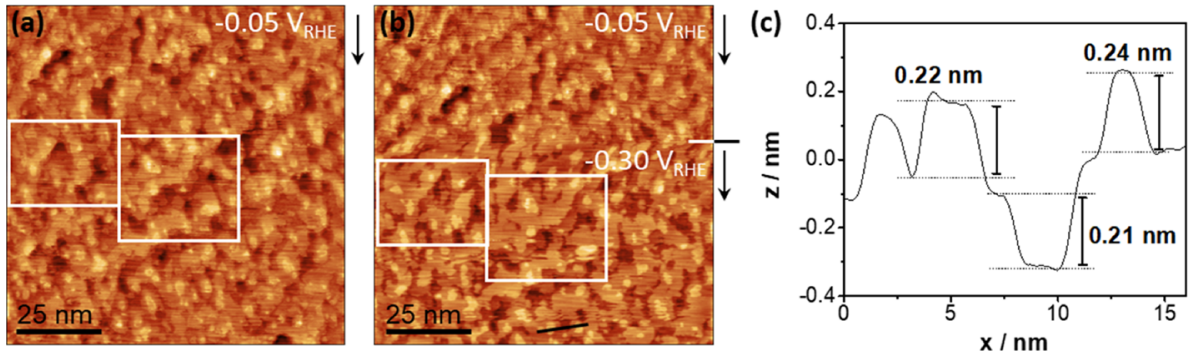

Figure 6. EC-STM visualization of morphological and structural changes of $\mathrm{Cu}(111) / 0.2 \mathrm{ML}$ of $\mathrm{Ni}(\mathrm{OH})_{2}$ during a potential step from -0.05 (a) to $-0.30 \mathrm{~V}_{\mathrm{RHE}}(\mathrm{b})$. (c) Corresponding line profile of the surface after the potential step at the position marked by the black line in panel (b). Images size $=(100 \times 100) \mathrm{nm}^{2} . I_{\text {tip }}=1 \mathrm{nA}$ and $E_{\text {tip }}=0.25 \mathrm{~V}_{\mathrm{RHE}}$. Black arrows mark the slow scan direction. Identical positions on the surface before and after the potential step are marked with white squares.

Figure S6). The appearance of a second pme was previously ascribed to the existence of different local values of pme on terrace and step sites. This could be caused by a preferential orientation of water on step sites with the oxygen toward the metal due to either a chemical preference or charge-dipole interactions because of a locally induced positive free charge at the steps in the corresponding potential region, resulting from a lower local value of pzfc. $^{38}$ In the case of $\mathrm{Cu}(111) / \mathrm{Ni}(\mathrm{OH})_{2}$, a similar explanation seems plausible. For coverages of only $0.1 \mathrm{ML}$ of $\mathrm{Ni}(\mathrm{OH})_{2}$, where we also observe an increase in $\mathrm{Cu}$ ad-island concentration, the step density might be too low for the appearance of a second pme, considering that the transients reflect the response of the whole surface. However, adding $0.2 \mathrm{ML}$ of $\mathrm{Ni}(\mathrm{OH})_{2}$ leads to a greater extent of roughening, where the surface consists of $3 \mathrm{D} \mathrm{Cu}$ ad-islands and holes. The roughness reaches a threshold where the local reorientation of water at the step sites triggers the turn-over of a significant fraction of the entire water ad-layer. In addition, the $\mathrm{Ni}(\mathrm{OH})_{2}$ is most likely situated at the step edges as suggested by the EC-STM images, which consequently increases their oxophilicity, and thus, the specific orientation of water molecules with the oxygen toward the metal is even more likely. Therefore, the inherent change in morphology of the $\mathrm{Cu}$ surface, which happens spontaneously upon deposition of $0.2 \mathrm{ML}$ of $\mathrm{Ni}(\mathrm{OH})_{2}$, leads to a higher disorder in the interfacial water structure at potentials close to the onset of the HER rationalizing the non-linear increase in electrocatalytic activity with increasing coverage. Direct comparison of the above presented LIPT results with the thermal coefficients of $\mathrm{Pt}(111)$ electrodes modified with various low amounts of $\mathrm{Ni}(\mathrm{OH})_{2}{ }^{12}$ where the electric field strength decreases linearly with increasing $\mathrm{Ni}(\mathrm{OH})_{2}$ coverage, can clearly rationalize the significant difference between the non-linear and linear HER activity enhancements of $\mathrm{Ni}(\mathrm{OH})_{2}$-modified $\mathrm{Cu}(111)$ and $\mathrm{Pt}(111)$, respectively. Furthermore, it was previously suggested that both the adsorption strength and the amount of adsorbed $\mathrm{OH}$ play a crucial role in the alkaline HER.,41 The addition of $\mathrm{Ni}(\mathrm{OH})_{2}$ and thus oxophilic sites can therefore not only play a part in the inversion of the potential transients at low potentials, i.e., the observed second pme at low potentials, but the consequent increase in adsorbed $\mathrm{OH}$, in the form of $\mathrm{Ni}(\mathrm{OH})_{2}$ species, can also chemically contribute to the HER activity enhancement. It is therefore likely that both the water dissociation, i.e., the cleavage of the water $\mathrm{O}-\mathrm{H}$ bond via the bifunctional mechanism, as well as the interfacial electric field strength, and thus, an efficient transport of reactants through the double layer are largely influenced by the presence of $\mathrm{Ni}(\mathrm{OH})_{2}$. Both effects can simultaneously contribute to the non-linear activity enhancement. Remarkably, the effect of the second pme is confined to a very narrow potential range between -0.18 and $-0.25 \mathrm{~V}_{\mathrm{RHE}}$. At more negative potentials, where the transients turn negative again, a decrease in the potential dependence of the thermal coefficient is recorded (Figure 5d). Since it has been recently found that $\mathrm{Cu}(111)$ reconstructs as a consequence of the change in free charge on the surface, ${ }^{14}$ we performed further in situ EC-STM imaging for $\mathrm{Cu}(111) / 0.2 \mathrm{ML}$ of $\mathrm{Ni}(\mathrm{OH})_{2}$ to examine possible further structural changes below the second pme.

Figure 6 shows a potential step from -0.05 to $-0.30 \mathrm{~V}_{\mathrm{RHE}}$. The lower potential lies in the region of the decrease in electric field strength. The $\mathrm{Cu}(111)$ electrode surface undergoes a smoothening process upon this potential step, where larger terraces with rounded edges are reformed. This process greatly resembles the so-called "electrochemical annealing", which was previously reported for, e.g., CO-covered $\mathrm{Ru}(0001)^{42}$ or $\mathrm{Cu}(111)$ in a benzotriazole solution. ${ }^{43}$ The adsorbate-induced or surfactant-induced smoothening was attributed to an enhanced mobility of the metal atoms. While chemical $\mathrm{Ni}(\mathrm{OH})_{2}$ deposition on $\mathrm{Cu}(111)$ leads to an overall roughening and a stabilization of $\mathrm{Cu}$ ad-islands, our ECSTM results at $-0.3 V_{\mathrm{RHE}}$ suggest that the difference in $\mathrm{Ni}(\mathrm{OH})_{2}$ binding to $\mathrm{Cu}$ at lower potentials, due to, e.g., an increase in negative free charge, enhances surface diffusion and mobility of the assumed $\mathrm{Ni}(\mathrm{OH})_{2}-\mathrm{Cu}_{\mathrm{ad}}$-complexes, which induces surface annealing. However, it cannot be excluded that the observed potential-dependent morphology changes may in addition be determined by the HER itself since $\mathrm{Cu}(100)^{25}$ and $\mathrm{Cu}(111)^{26}$ have been found to reconstruct at or close to the onset of the HER in acidic media. Generally, the $\mathrm{Ni}(\mathrm{OH})_{2}$ modification leads to drastic morphological changes where the variation of the binding of $\mathrm{Ni}(\mathrm{OH})_{2}$, in combination with the change of the free charge on the electrode, seems to result in a potential-dependent restructuring. However, only coverages of $0.2 \mathrm{ML}$ of $\mathrm{Ni}(\mathrm{OH})_{2}$ create a second pme close to the onset of the HER in alkaline media, where not only a mobile and dynamic surface but also a highly disordered water network is present, which facilitates the HER by lowering the energy barrier for charge movement across the interfacial water layer.

\section{CONCLUSIONS}

In summary, we have demonstrated that modifying $\mathrm{Cu}(111)$ with low amounts of $\mathrm{Ni}(\mathrm{OH})_{2}$ leads to an unusual non-linear trend in the enhancement of the HER in alkaline media with increasing coverage, which is in remarkable contrast to the $\mathrm{Ni}(\mathrm{OH})_{2}$-modified Pt electrode characteristics, where a linear dependence of activity and $\mathrm{Ni}(\mathrm{OH})_{2}$ concentration is 
observed. Adding only $0.1 \mathrm{ML}$ of $\mathrm{Ni}(\mathrm{OH})_{2}$ to the $\mathrm{Cu}$ surface does not lead to a significant activity increase in the HER, whereas for $\mathrm{Ni}(\mathrm{OH})_{2}$ coverages of $0.2 \mathrm{ML}$, the reaction is enhanced by a factor of 13 relative to the bare $\mathrm{Cu}(111)$. While there is no difference in the apparent oxidation state of $\mathrm{Cu}$ on the surface, as determined by XPS, in situ EC-STM reveals that upon $\mathrm{Ni}(\mathrm{OH})_{2}$ deposition, the surface drastically restructures, which leads to $\mathrm{Cu}$ ad-island nucleation and growth in the case of $0.1 \mathrm{ML}$ of $\mathrm{Ni}(\mathrm{OH})_{2}$ and even a 3D roughening of the surface for $0.2 \mathrm{ML}$. This generic instability of $\mathrm{Cu}$ surfaces gives rise to a completely different molecular-level picture, which does not corroborate the previously found cluster-based mechanism on Pt electrodes, where $\mathrm{Ni}(\mathrm{OH})_{2}$ forms distinct nanometer-sized $3 \mathrm{D}$ structures serving as active sites for an enhanced water dissociation. Surprisingly, the roughness of the $\mathrm{Cu}$ surfaces continuously increases upon adding more $\mathrm{Ni}(\mathrm{OH})_{2}$ and thus does not clearly correlate with the observed non-linear activity trend. Laser-induced potential transients, however, reveal that only for $\mathrm{Cu}(111)$ modified with $0.2 \mathrm{ML}$ of $\mathrm{Ni}(\mathrm{OH})_{2}$ a second pme exists, which points to the presence of a highly disordered water ad-layer close to the onset of the HER, whereas there is no significant decrease in the electric field strength for $0.1 \mathrm{ML}$ of $\mathrm{Ni}(\mathrm{OH})_{2}$ compared to $\mathrm{Cu}(111)$. Our results therefore highlight the significant role of the interfacial water network for the electrocatalytic performance of a material, where an increase in disorder of the water adlayer promotes charge transfer through the double layer, which drastically enhances the efficiency of the HER.

\section{EXPERIMENTAL METHODS}

4.1. Chemicals and Materials. $\mathrm{NaOH}$ electrolyte solutions $(0.1 \mathrm{M})$ were prepared by using sodium hydroxide monohydrate (Merck, Suprapur) and aqueous $\mathrm{Ni}^{2+}$-containing solutions $(0.0001$ and $0.01 \mathrm{M}$ nickel sulfate hexahydrate, Alfa Aesar, $>99.97 \%$, metal basis). All solutions were prepared with ultrapure water (Milli-Q purification system, $>18 \mathrm{M} \Omega \mathrm{cm}$, Merck). For deaerating the electrolytes, Ar gas (Messer, 5.0) was used. The $\mathrm{Cu}(111)$ single-crystal electrodes (Mateck, Jülich) were mechanically polished with diamond paste $(3,1$, and $0.25 \mu \mathrm{m}, \mathrm{ESCIL})$ and subsequently electropolished in $60 \%$ $\mathrm{H}_{3} \mathrm{PO}_{4}$ (85\% EMSURE, Merck) at $1.8 \mathrm{~V}$ vs a $\mathrm{Cu}$ counter electrode and thoroughly rinsed with Milli-Q water. Prior to the STM experiments, the crystals were additionally annealed in a homemade horizontal tube furnace under $\mathrm{H}_{2}$ flow after electropolishing and transferred to a glovebox (MBraun $\mathrm{MB}$ 200 MOD) without any contact to air.

$\mathrm{Ni}(\mathrm{OH})_{2}$ deposition was performed by immersing the freshly electropolished $\mathrm{Cu}(111)$ single-crystal electrodes in aqueous $\mathrm{NiSO}_{4}$ solution for $1 \mathrm{~min}$ at open circuit potential, i.e., without any external potential or current applied. By employing differently diluted $\mathrm{Ni}^{2+}$ solutions with concentrations of either 0.0001 or $0.01 \mathrm{M}$, two different coverages of 0.1 and $0.2 \mathrm{ML} \mathrm{Ni}(\mathrm{OH})_{2}$ were formed. The modified $\mathrm{Cu}(111)$ electrodes were rinsed with $\mathrm{NaOH}$ solution after deposition and immersed at $0 \mathrm{~V}$ vs the reversible hydrogen electrode (RHE).

4.2. Electrochemistry. All electrochemical experiments were performed in a three electrode configuration, where the electrochemical cell included a Teflon beaker for the alkaline electrolyte to avoid any glass contamination. ${ }^{44} \mathrm{~A}$ carbon rod counter and a polytetrafluoroethylene (PTFE, 60\% dispersion in water, Sigma Aldrich) bound activated carbon (YP-50F, Kuraray) quasi-reference (AC-QRE), which is described in detail in ref 45 , were used to perform cyclic voltammetry. All potentials were converted to the reversible hydrogen electrode (RHE) scale. The $\mathrm{Cu}(111)$ working electrode was examined in hanging meniscus configuration. The electrochemical measurements were performed on either an eDAQEA161 potentiostat connected to a signal generator (PAR 173) and an eDAQ ED401 digital recorder or on a Biologic VSP 300 potentiostat.

For the online differential electrochemical mass spectrometry (DEMS) measurements, a Hiden HPR-40 mass spectrometer in combination with a commercial flow cell (PEEK, Type A, Hiden Analytical, U.K.) was used. The interface between the high vacuum and the cell was a porous PTFE membrane (Gore-Tex, thickness of $75 \mathrm{~mm}$, pore diameter of $0.02 \mu \mathrm{m}$, and a porosity of $50 \%)$. For both the counter and reference electrodes, PTFE bound activated carbon was used.

4.3. Quasi In Situ X-ray Photoelectron Spectroscopy. X-ray photoelectron spectroscopy (XPS) characterization was performed on a MultiLab 2000 instrument (Thermo Fisher Scientific) using a hemispherical sector analyzer (Alpha 110, Thermo Fischer Scientific) and a monochromatic $\mathrm{Al} \mathrm{K} \alpha \mathrm{X}$-ray source $(1486.6 \mathrm{eV})$. The measurements were carried out with a take-off angle of $60^{\circ}$ between the sample and analyzer to enhance surface sensitivity. The XPS spectra were recorded at a pass energy of $25 \mathrm{eV}$ and an energy step size of $0.01 \mathrm{eV}$. Pretreatment and $\mathrm{Ni}(\mathrm{OH})_{2}$ deposition were performed inside an Ar-filled glovebox, in exactly the same way as for all the electrochemical measurements. After several voltammetric cycles, all the electrodes ( $\mathrm{Cu}(111), \mathrm{Cu}(111) / 0.1 \mathrm{ML}$ of $\mathrm{Ni}(\mathrm{OH})_{2}$, and $\mathrm{Cu}(111) / 0.2 \mathrm{ML}$ of $\left.\mathrm{Ni}(\mathrm{OH})_{2}\right)$ were removed from the electrolyte under potential control $\left(0 \mathrm{~V}_{\mathrm{RHE}}\right)$ and transported to an XPS analyzing chamber in a home-built transfer cell without exposure to ambient air by the additional use of a portable glovebox attached to the transfer chamber of the XPS. ${ }^{46}$

4.4. In Situ Electrochemical Scanning Tunneling Microscopy. Electrochemical scanning tunneling microscopy (EC-STM) experiments were performed on a Keysight 5500 scanning probe microscope, which was placed inside an Arfilled glovebox (MBraun MB $200 \mathrm{MOD}$ ) to avoid any oxygen infiltration during the measurements. A home-built polychlorotrifluoroethylene (PCTFE) EC-STM cell was used, where both counter and reference electrodes consisted of PTFE bound activated carbon. ${ }^{45}$ STM tips were prepared by electrochemical etching of a tungsten wire (Advent, 99.9\%) and subsequent coating with Apiezon wax to avoid leak currents. The $\mathrm{Cu}(111)$ electrode was immersed at open circuit potential, and the formed thin native copper oxide was reduced prior to every experiment. Before imaging, cyclic voltammograms were recorded inside the EC-STM cell to ensure clean conditions and the stability of the system. The metallic surface was consistently imaged prior to any $\mathrm{Ni}(\mathrm{OH})_{2}$ deposition to ensure high surface quality. For data analysis and representation of the STM images, Gwyddion ${ }^{47}$ was employed.

4.5. Laser-Induced Temperature Jump Method. The detailed procedure of the laser-induced temperature jump technique employed in this work was described previously elsewhere. $^{35,37,48}$ Shortly, a four-electrode cell configuration was used, where the electrolyte was filled inside a Teflon piece, which was pressed onto the quartz window and allowed for an electrolyte volume of around 3 to $4 \mathrm{~mL}{ }^{35} \mathrm{~A} \mathrm{Pd}-\mathrm{H}_{2}$ reference electrode and two $\mathrm{Au}$ auxiliary electrodes were used. A NdYAG laser (Brilliant B, Quantel, $532 \mathrm{~nm}$ ) was used with a pulse 
duration of $5 \mathrm{~ns}$ and a beam diameter of $6 \mathrm{~mm}$. The energy density was reduced to $20 \mathrm{~mJ} / \mathrm{cm}^{2}$. After several voltammetric cycles, around 100 coulostatic potential transients were recorded and averaged with a Tektronix model TDS 3054B oscilloscope.

\section{ASSOCIATED CONTENT}

\section{SI Supporting Information}

The Supporting Information is available free of charge at https://pubs.acs.org/doi/10.1021/acscatal.1c02673.

Calculation of the apparent $\mathrm{Ni}(\mathrm{OH})_{2}$ coverages, statistical evaluation of the surface roughness, 3D laser transient plots, determination of the thermal coefficients, corrections for thermodiffusion potential, and dependence of the pme with coverages (PDF)

\section{AUTHOR INFORMATION}

\section{Corresponding Authors}

Víctor Climent - Instituto Universitario de Electroquímica, Universidad de Alicante, E-03690 San Vicente del Raspeig, Alicante, Spain; 이이.org/0000-0002-2033-5284; Email: victor.climent@ua.es

Julia Kunze-Liebhäuser - Institute of Physical Chemistry, University of Innsbruck, Innsbruck 6020, Austria; 다이.org/0000-0002-8225-3110; Email: julia.kunze@ uibk.ac.at

\section{Authors}

Andrea Auer - Institute of Physical Chemistry, University of Innsbruck, Innsbruck 6020, Austria; 이이이.org/00000002-8004-1587

Francisco J. Sarabia - Instituto Universitario de Electroquímica, Universidad de Alicante, E-03690 San Vicente del Raspeig, Alicante, Spain

Daniel Winkler - Institute of Physical Chemistry, University of Innsbruck, Innsbruck 6020, Austria; ○ orcid.org/00000002-5939-0096

Christoph Griesser - Institute of Physical Chemistry, University of Innsbruck, Innsbruck 6020, Austria

Juan M. Feliu - Instituto Universitario de Electroquímica, Universidad de Alicante, E-03690 San Vicente del Raspeig, Alicante, Spain; 이이이.org/0000-0003-4751-3279

Complete contact information is available at:

https://pubs.acs.org/10.1021/acscatal.1c02673

\section{Notes}

The authors declare no competing financial interest.

\section{ACKNOWLEDGMENTS}

A.A. is a recipient of a doctorate (DOC) Fellowship of the Austrian Academy of Sciences at the Institute of Physical Chemistry. C.G. thanks the Austrian Research Promotion Agency (FFG) for funding via the project number 870523 . J.K.-L. acknowledges funding by the Austrian Science Fund (FWF) via grant I-4114-N37. J.M.F. and V.C. acknowledge financial support from Ministerio de Ciencia e Innovación (project PID2019-105653GB-100) and Generalitat Valenciana (project PROMETEO/2020/063).

\section{REFERENCES}

(1) Lasia, A. Hydrogen Evolution Reaction. In Handbook of Fuel Cells - Fundamentals, Technology and Applications; Vielstich, W.,
Gasteiger, H. A., Lamm, A., Yokokawa, H., Eds.; John Wiley \& Sons: 2014; pp. 1-25, DOI: 10.1007/978-1-4419-6996-5_403

(2) Breiter, M. W. Reaction Mechanisms of the $\mathrm{H}_{2}$ Oxidation/ Evolution Reaction. In Handbook of Fuel Cells - Fundamentals, Technology and Applications; Vielstich, W., Gasteiger, H. A., Lamm, A., Yokokawa, H., Eds.; John Wiley \& Sons: 2010; pp. 1-7, DOI: 10.1002/9780470974001.f204027

(3) Marković, N. M.; Ross, P. N., Jr. Surface Science Studies of Model Fuel Cell Electrocatalysts. Surf. Sci. Rep. 2002, 45, 117-229.

(4) Dubouis, N.; Grimaud, A. The Hydrogen Evolution Reaction: From Material to Interfacial Descriptors. Chem. Sci. 2019, 10, 91659181.

(5) Strmcnik, D.; Lopes, P. P.; Genorio, B.; Stamenkovic, V. R.; Markovic, N. M. Design Principles for Hydrogen Evolution Reaction Catalyst Materials. Nano Energy 2016, 29, 29-36.

(6) Subbaraman, R.; Tripkovic, D.; Strmcnik, D.; Chang, K.-C.; Uchimura, M.; Paulikas, A. P.; Stamenkovic, V.; Markovic, N. M. Enhancing Hydrogen Evolution Activity in Water Splitting by Tailoring $\mathrm{Li}^{+}-\mathrm{Ni}(\mathrm{OH})_{2}$-Pt Interfaces. Science 2011, 334, 1256-1260.

(7) Subbaraman, R.; Tripkovic, D.; Chang, K. C.; Strmcnik, D.; Paulikas, A. P.; Hirunsit, P.; Chan, M.; Greeley, J.; Stamenkovic, V.; Markovic, N. M. Trends in Activity for the Water Electrolyser Reactions on 3d M(Ni,Co,Fe,Mn) Hydr(oxy)Oxide Catalysts. Nat. Mater. 2012, 11, 550-557.

(8) Danilovic, N.; Subbaraman, R.; Strmcnik, D.; Chang, K.-C.; Paulikas, A. P.; Stamenkovic, V. R.; Markovic, N. M. Enhancing the Alkaline Hydrogen Evolution Reaction Activity through the Bifunctionality of $\mathrm{Ni}(\mathrm{OH})_{2} /$ Metal Catalysts. Angew. Chem. 2012, 124, 12663-12666.

(9) Stamenkovic, V. R.; Strmcnik, D.; Lopes, P. P.; Markovic, N. M. Energy and Fuels from Electrochemical Interfaces. Nat. Mater. 2017, $16,57-69$.

(10) Martins, P. F. B. D.; Lopes, P. P.; Ticianelli, E. A.; Stamenkovic, V. R.; Markovic, N. M.; Strmcnik, D. Hydrogen Evolution Reaction on Copper: Promoting Water Dissociation by Tuning the Surface Oxophilicity. Electrochem. Commun. 2019, 100, 30-33.

(11) Ledezma-Yanez, I.; Wallace, W. D. Z.; Sebastián-Pascual, P.; Climent, V.; Feliu, J. M.; Koper, M. T. M. Interfacial Water Reorganization as a pH-Dependent Descriptor of the Hydrogen Evolution Rate on Platinum Electrodes. Nat. Energy 2017, 2, 17031.

(12) Sarabia, F. J.; Sebastián-Pascual, P.; Koper, M. T. M.; Climent, V.; Feliu, J. M. Effect of the Interfacial Water Structure on the Hydrogen Evolution Reaction on Pt(111) Modified with Different Nickel Hydroxide Coverages in Alkaline Media. ACS Appl. Mater. Interfaces 2019, 11, 613-623.

(13) Tiwari, A.; Heenen, H. H.; Bjørnlund, A. S.; Maagaard, T.; Cho, E.; Chorkendorff, I.; Kristoffersen, H. H.; Chan, K.; Horch, S. Fingerprint Voltammograms of Copper Single Crystals under Alkaline Conditions: A Fundamental Mechanistic Analysis. J. Phys. Chem. Lett. 2020, 11, 1450-1455.

(14) Auer, A.; Ding, X.; Bandarenka, A. S.; Kunze-Liebhäuser, J. The Potential of Zero Charge and the Electrochemical Interface Structure of $\mathrm{Cu}(111)$ in Alkaline Solutions. J. Phys. Chem. C 2021, 125, 50205028.

(15) Bockris, J. O.; Reddy, A. K. N. Modern Electrochemistry; Plenum Press: New York, 1970. pp. 1231-1251.

(16) Foelske-Schmitz, A. X-Ray Photoelectron Spectroscopy in Electrochemistry Research. In Encyclopedia of Interfacial Chemistry; Wandelt, K., Ed.; Elsevier: 2018; pp. 591-606, DOI: 10.1016/B9780-12-409547-2.11549-5.

(17) Panzner, G.; Egert, B.; Schmidt, H. P. The Stability of $\mathrm{CuO}$ and $\mathrm{Cu}_{2} \mathrm{O}$ Surfaces during Argon Sputtering Studied by XPS and AES. Surf. Sci. 1985, 151, 400-408.

(18) Biesinger, M. C. Advanced Analysis of Copper X-Ray Photoelectron Spectra. Surf. Interface Anal. 2017, 49, 1325-1334.

(19) Biesinger, M. C.; Lau, L. W. M.; Gerson, A. R.; Smart, R. S. C. The Role of the Auger Parameter in XPS Studies of Nickel Metal, Halides and Oxides. Phys. Chem. Chem. Phys. 2012, 14, 2434-2442. 
(20) Arenz, M.; Broekmann, P.; Lennartz, M.; Vogler, E.; Wandelt, K. In-Situ Characterization of Metal/Electrolyte Interfaces: Sulfate Adsorption on $\mathrm{Cu}(111)$. Phys. Status Solidi A 2001, 187, 63-74.

(21) Broeckmann, P.; Wilms, M.; Arenz, M.; Sp, A.; Wandelt, K. Atomic Structure of $\mathrm{Cu}(111)$ Surfaces in Dilute Sulfuric Acid Solution. In Solid-Liquid Interfaces. Topics in Applied Physics; Wandelt, K., Thurgate, S., Eds.; Springer: Berlin, Heidelberg, 2003; pp. 141-199, DOI: 10.1007/3-540-44817-9_5

(22) Maurice, V.; Strehblow, H.-H.; Marcus, P. In Situ STM Study of the Initial Stages of Anodic Oxidation of $\mathrm{Cu}(111)$ in Aqueous Solution. Surf. Sci. 2003, 458, 185-194.

(23) Kunze, J.; Maurice, V.; Klein, L. H.; Strehblow, H. H.; Marcus, P. In Situ STM Study of the Effect of Chlorides on the Initial Stages of Anodic Oxidation of $\mathrm{Cu}(111)$ in Alkaline Solutions. Electrochim. Acta 2003, 48, 1157-1167.

(24) Kunze-Liebhäuser, J. Electrochemical Scanning Tunneling Microscopy Studies of Copper Oxide Formation-A Review. In Encyclopedia of Interfacial Chemistry; Wandelt, K., Ed.; Elsevier: 2018; pp. $107-120$.

(25) Matsushima, H.; Taranovskyy, A.; Haak, C.; Gründer, Y.; Magnussen, O. M.; Gründer, Y.; Magnussen, O. M.; Gründer, Y.; Magnussen, O. M. Reconstruction of $\mathrm{Cu}(100)$ Electrode Surfaces during Hydrogen Evolution. J. Am. Chem. Soc. 2009, 131, 1036210363 .

(26) Huynh, T. M. T.; Broekmann, P. From In Situ towards In Operando Conditions: Scanning Tunneling Microscopy Study of Hydrogen Intercalation in $\mathrm{Cu}(111)$ during Hydrogen Evolution. ChemElectroChem 2014, 1, 1271-1274.

(27) Huang, J.; Hörmann, N.; Oveisi, E.; Loiudice, A.; De Gregorio, G. L.; Andreussi, O.; Marzari, N.; Buonsanti, R. Potential-Induced Nanoclustering of Metallic Catalysts during Electrochemical $\mathrm{CO}_{2}$ Reduction. Nat. Commun. 2018, 9, 3117.

(28) Kim, Y. G.; Javier, A.; Baricuatro, J. H.; Torelli, D.; Cummins, K. D.; Tsang, C. F.; Hemminger, J. C.; Soriaga, M. P. Surface Reconstruction of Pure- $\mathrm{Cu}$ Single-Crystal Electrodes under COReduction Potentials in Alkaline Solutions: A Study by Seriatim ECSTM-DEMS. J. Electroanal. Chem. 2016, 780, 290-295.

(29) Simon, G. H.; Kley, C. S.; Cuenya, B. R. Potential-Dependent Morphology of Copper Catalysts During $\mathrm{CO}_{2}$ Electroreduction Revealed by In Situ Atomic Force Microscopy. Angew. Chem., Int. Ed. 2021, 60, 2561-2568.

(30) Auer, A.; Andersen, M.; Wernig, E. M.; Hörmann, N. G.; Buller, N.; Reuter, K.; Kunze-Liebhäuser, J. Self-Activation of Copper Electrodes during CO Electro-Oxidation in Alkaline Electrolyte. Nat. Catal. 2020, 3, 797-803.

(31) Eren, B.; Zherebetskyy, D.; Patera, L. L.; Wu, C. H.; Bluhm, H.; Africh, C.; Wang, L.-W.; Somorjai, G. A.; Salmeron, M. Activation of $\mathrm{Cu}(111)$ Surface by Decomposition into Nanoclusters Driven by CO Adsorption. Science 2016, 351, 475-478.

(32) Poensgen, M.; Wolf, J. F.; Frohn, J.; Giesen, M.; Ibach, H. Step Dynamics on $\mathrm{Ag}(111)$ and $\mathrm{Cu}(100)$ Surfaces. Surf. Sci. 1992, 274, 430-440.

(33) Eren, B.; Zherebetskyy, D.; Hao, Y.; Patera, L. L.; Wang, L. W.; Somorjai, G. A.; Salmeron, M. One-Dimensional Nanoclustering of the $\mathrm{Cu}(100)$ Surface under CO Gas in the Mbar Pressure Range. Surf. Sci. 2016, 651, 210-214.

(34) Roiaz, M.; Falivene, L.; Rameshan, C.; Cavallo, L.; Kozlov, S. M.; Rupprechter, G. Roughening of Copper (100) at Elevated CO Pressure: $\mathrm{Cu}$ Adatom and Cluster Formation Enable CO Dissociation. J. Phys. Chem. C 2019, 123, 8112-8121.

(35) Sebastián-Pascual, P.; Sarabia, F. J.; Climent, V.; Feliu, J. M.; Escudero-Escribano, M. Elucidating the Structure of the Cu-Alkaline Electrochemical Interface with the Laser-Induced Temperature Jump Method. J. Phys. Chem. C 2020, 124, 23253-23259.

(36) Climent, V.; Coles, B. A.; Compton, R. G. Laser-Induced Potential Transients on a $\mathrm{Au}(111)$ Single-Crystal Electrode. Determination of the Potential of Maximum Entropy of DoubleLayer Formation. J. Phys. Chem. B 2002, 106, 5258-5265.
(37) Climent, V.; Coles, B. A.; Compton, R. G. Coulostatic Potential Transients Induced by Laser Heating of a $\mathrm{Pt}(111)$ Single-Crystal Electrode in Aqueous Acid Solutions. Rate of Hydrogen Adsorption and Potential of Maximum Entropy. J. Phys. Chem. B 2002, 106, 5988-5996.

(38) García-Aráez, N.; Climent, V.; Feliu, J. M. Potential-Dependent Water Orientation on $\mathrm{Pt}(111)$ Stepped Surfaces from Laser-Pulsed Experiments. Electrochim. Acta 2009, 54, 966-977.

(39) Huang, J.; Malek, A.; Zhang, J.; Eikerling, M. H. NonMonotonic Surface Charging Behavior of Platinum: A Paradigm Change. J. Phys. Chem. C 2016, 120, 13587-13595.

(40) García-Aráez, N.; Climent, V.; Feliu, J. M. 1 Temperature Effects on Platinum Single-Crystal/Aqueous Solution Interphases. Combining Gibbs Thermodynamics with Laser-Pulsed Experiments. In Interfacial Phenomena in Electrocatalysis; Vayenas, C. G., Ed.; Springer: 2011; pp. 1-106, DOI: 10.1007/978-1-4419-5580-7_1.

(41) McCrum, I. T.; Koper, M. T. M. The Role of Adsorbed Hydroxide in Hydrogen Evolution Reaction Kinetics on Modified Platinum. Nat. Energy 2020, 5, 891-899.

(42) Zei, M. S.; Ertl, G. Structural Changes of a Ru(0001) Surface under the Influence of Electrochemical Reactions. Phys. Chem. Chem. Phys. 2000, 2, 3855-3859.

(43) Polewska, W.; Vogt, M. R.; Magnussen, O. M.; Behm, R. J. In Situ STM Study of $\mathrm{Cu}(111)$ Surface Structure and Corrosion in Pure and Benzotriazole-Containing Sulfuric Acid Solution. J. Phys. Chem. B 1999, 103, 10440-10451.

(44) Tiwari, A.; Maagaard, T.; Chorkendorff, I.; Horch, S. Effect of Dissolved Glassware on the Structure-Sensitive Part of the $\mathrm{Cu}(111)$ Voltammogram in KOH. ACS Energy Lett. 2019, 4, 1645-1649.

(45) Auer, A.; Kunze-Liebhäuser, J. A Universal Quasi-Reference Electrode for in Situ EC-STM. Electrochem. Commun. 2019, 98, 1518.

(46) Watschinger, M.; Ploner, K.; Winkler, D.; Kunze-Liebhäuser, J.; Klötzer, B.; Penner, S. Operando Fourier-Transform Infrared-Mass Spectrometry Reactor Cell Setup for Heterogeneous Catalysis with Glovebox Transfer Process to Surface-Chemical Characterization. Rev. Sci. Instrum. 2021, 92, No. 024105.

(47) Nečas, D.; Klapetek, P. Gwyddion: An Open-Source Software for SPM Data Analysis. Open Phys. 2012, 10, 181-188.

(48) García-Aráez, N.; Climent, V.; Feliu, J. M. Evidence of Water Reorientation on Model Electrocatalytic Surfaces from NanosecondLaser-Pulsed Experiments. J. Am. Chem. Soc. 2008, 130, 3824-3833. 